Revista Brasileira de Meteorologia, v.25, n.4, 535 - 542, 2010

\title{
ASPECTOS ENERGÉTICOS DO DESENVOLVIMENTO DA CANA-DE-AÇÚCAR. PARTE 2: BALANÇO DE ENERGIA E PARÂMETROS DERIVADOS
}

\author{
ROMISIO GERALDO BOUHID ANDRÉ ${ }^{1}$, JOSÉ CARLOS MENDONÇA ${ }^{2}$, FRANCISCA MARIA ALVES \\ PINHEIRO $^{2}$, VALDO DA SILVA MARQUES ${ }^{2}$ E JOSÉ MARQUES $^{3}$ \\ ${ }^{1}$ Instituto Nacional de Meteorologia (INMET/MAPA), Brasília, DF \\ ${ }^{2}$ Laboratório de Meteorologia, Universidade Estadual Norte Fluminense (LAMET/CCT/UENF ), Macaé, RJ \\ ${ }^{3}$ Consultor, Rio de Janeiro, RJ
}

romisio.andre@inmet.gov.br, mendonca@uenf.br, \{valdo; francisca\}@lenep.uenf.br, marques1936@yahoo.com.br

Recebido Setembro 2008 - Aceito Março 2010

\begin{abstract}
RESUMO
Um experimento foi instalado em Campos dos Goytacazes, RJ, numa parcela de 5 ha cultivada com

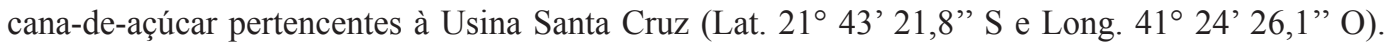
Foram coletados dados de saldo de radiação solar $(R n)$, do fluxo de calor no solo $(G)$, dos gradientes de temperatura de ar (Tar), de umidade relativa $(U R)$ e da velocidade do vento $(V)$. Os instrumentos foram instalados a 0,40 e 2,40 m acima do dossel vegetal e deslocados com o crescimento da cultura. Foram analisados dados de quatro períodos sendo um no estádio de perfilamento (109 DAP - Dias Após o Plantio), dois no estádio de desenvolvimento dos colmos (197 e 260 DAP) e um no estádio de maturação (339 DAP). O fluxo de vapor d'água ( $L E)$ foi estimado pela equação de Penman e Monteith, e, o fluxo de calor sensível $(H)$ foi obtido de forma residual da equação do balanço. Os resultados obtidos indicam que a relação $L E / R n$ apresentou valores crescentes com o aumento do índice de área foliar (IAF), sendo o valor médio igual a 0,79 para um IAF entre 2,0 e 3,0; 0,87 para IAF entre 5,0 e 6,0; 0,99 para IAF entre 7,0 e 8,0 e 1,23 para IAF entre 8,0 e 9,0.

Os coeficientes angulares das regressões lineares entre $R n$ e $G$ apresentaram, nos quatro períodos analisados, valores de 0,$091 ; 0,071 ; 0,040$ e 0,040 respectivamente e, a Evapotranspiração Potencial - ETP mostrou valores médios de 5,12 $\mathrm{mm}, 6,17 \mathrm{~mm}, 5,04 \mathrm{~mm}$ e 4,62 $\mathrm{mm}$ respectivamente, nos quatro períodos analisados.
\end{abstract}

Palavras-Chaves: Balanço de energia, fluxo de calor no solo, fluxo de vapor d'água, cana-de-açúcar

\begin{abstract}
ENERGY ASPECTS ON THE SUGAR CANE DEVELOPMENT. PART 2: ENERGY BALANCE AND DERIVED PARAMETERS

An experiment was carried out in the Campos dos Goytacazes County, RJ, in a 5 hectares sugar cane

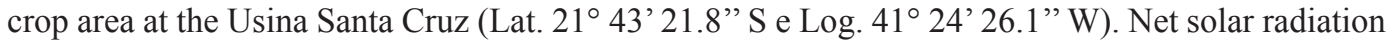
$(R n)$, heat flow in the soil $(G)$, air temperature gradient $(T a r)$, relative humidity $(U R)$ and wind velocity $(V)$ data were collected. Instruments were installed at 0.40 and $2.40 \mathrm{~m}$ above the canopy and moved up with crop growth. Data from four periods were analyzed for the following stages: one in the tillering (109 DAP - days after planting), two during the development of sprouts (197 and 260 DAP) and one in the maturation (339 DAP). Latent heat flux $(L E)$ was estimated by Penman e Monteith equation. Sensible heat flux $(H)$ was obtained from balance equation residual. The results indicate that the relation $L E / R n$ presented increasing values with leaf area index (LAI), with a mean value equal to 0.79 for a LAI between 2.0 and 3.0; 0.87 for a LAI between 5.0 and 6.0: 0,99 for LAI between 7.0 and 8.0 and 1.23 for LAI between 8.0 and 9.0. The angular coefficient of the linear regression between $R n$ and $G$ presented values 0.091, 0.071 and 0.040, mean daily Potential Evapotranspiration - PE values of $5.12 \mathrm{~mm}, 6.17 \mathrm{~mm}, 5.04 \mathrm{~mm}$ and $4.62 \mathrm{~mm}$ for the four days respectively.
\end{abstract}

Keywords: Energy balance, soil heat flux, water-vapor flux, sugarcane 


\section{INTRODUÇÃO}

A importância das trocas de propriedades conservativas entre a comunidade vegetal e o meio que a envolve, como momentum, calor latente, calor sensível e outros são evidenciados pela influência que desempenham nos processos fisiológicos das plantas, bem como na ocorrência de pragas e doenças, o que condiciona o potencial produtivo das espécies vegetais exploradas economicamente (Frota, 1978).

As medidas dos componentes do balanço de radiação e de energia em condições de campo têm aplicabilidade direta em práticas agrícolas, principalmente no planejamento racional da irrigação, no uso adequado do solo, no zoneamento agrícola regional, no impacto das variações meteorológicas sobre os cultivos agrícolas, na proteção de plantas, entre outros. $\mathrm{O}$ avanço dos conhecimentos meteorológicos em micro-escala, bem como a evolução da tecnologia instrumental de monitoramento tem propiciado um aumento das pesquisas nesta área do conhecimento.

Os estudos sobre o balanço de energia de uma superfície natural se baseiam no princípio de conservação da energia. Por meio da contabilização dos componentes que integram esse balanço, pode-se avaliar as parcelas do saldo de radiação utilizadas para os fluxos de calor sensível e latente. A razão de Bowen ( $\beta$ ) tem sido bastante utilizada para resolver a equação do balanço de energia. Villa Nova (1973) resolveu a equação do balanço para uma cultura de arroz irrigado. Pedro Junior (1977), Viswanadham e André (1983), utilizaram-na para a partição do balanço sobre uma cultura de soja e Sá et al. (1988) aplicaram-na para a Floresta Amazônica.

Outros autores, como Alfonsi et al. (1986), Bergamaschi et al. (1988), Cunha et al. (1989), Fontana et al. (1991), Cunha e Bergamaschi (1994), Mendonça (2007) também utilizaram a razão de Bowen na partição do saldo de radiação.

Valores negativos da razão de Bowen ( $\beta$ ) significam que está havendo transporte de calor sensível do ar mais quente para a superfície mais fria, condição de advecção ou de inversão térmica. Nesses casos, o fluxo de calor latente $(\lambda \mathrm{E})$ pode até suplantar o saldo de radiação $(\mathrm{Rn})$, pois o fluxo de calor sensível $(\mathrm{H})$ representa um adicional de energia disponível à superfície evaporante.

Segundo Verma et al. (1978), a suposição de igualdade entre os coeficientes de difusão turbulenta, para o calor sensível e vapor d'água sob condições de advecção de calor sensível, pode causar erros significativos nas estimativas do fluxo de calor latente $(\lambda E)$ efetuadas pelo método do balanço de energia. Para contornar o problema e corrigir esses erros, propuseram um fator de correção para estabilidade atmosférica, em função dos gradientes de temperatura e de pressão de vapor.

Oliveira e Silva (1990) citam que ao se estudar a advecção de calor sensível sobre uma área vegetada, três situações podem identificar as fontes de origem do ar: advecção entre fileiras, causada pela exposição do solo entre o dossel; advecção de bordadura ou local, originada por corrente de ar quente proveniente de superfícies com descontinuidade de temperatura, umidade e rugosidade; e advecção regional ou de larga-escala, massas de ar quente e seco originadas em regiões quentes e secas, que se movem através de uma superfície vegetada úmida.

Toledo Filho (2001) ajustou o modelo de Penman e Monteih para o cálculo da evapotranspiração da cultura da cana-de-açúcar, na zona canavieira de Alagoas, a partir de determinações micrometeorológicas do balanço de energia razão de Bowen, nos diferentes estádios do desenvolvimento da cultura e em diferentes condições de demanda atmosférica. Mostrou que o fluxo de calor latente representou a maior parcela do saldo de radiação, sendo de $78 \%$ de Rn e o fluxo de calor sensível de $21 \%$ deste, e concluiu que a equação de Penman e Monteith se presta perfeitamente para a estimativa da evapotranspiração da cultura da cana-de-açúcar na zona canavieira do Estado de Alagoas.

Moura et al. (2007) fizeram determinações do fluxo de calor latente e demais componentes do balanço de energia, com base na razão de Bowen, para cultura de cana-de-açúcar variedade RB92-576(cana planta), no vale do São Francisco, Juazeiro-BA. Mostraram que o fluxo de calor latente representou $82 \%$ do saldo de radiação.

Dessa maneira, o objetivo deste trabalho foi analisar as variações nos componentes do balanço de energia e estimar a Evapotranspiração Potencial - ETP, para a cultura de cana-deaçúcar em Campos dos Goytacazes, RJ.

\section{MATERIAL E MÉTODOS}

\section{1 Área Experimental e Cultura utilizada}

O experimento foi instalado em uma parcela de 5 ha, pertencentes à Usina Santa Cruz (latitude: $21^{\circ} 43^{\prime} 21,8^{\prime \prime}$; longitude: $41^{\circ} 24^{\prime} 26,1^{\prime \prime} \mathrm{O}$; altitude: $\left.11 \mathrm{~m}\right)$. O solo do local é caracterizado como Cambissolo, com textura muito argilosa e relevo plano (Embrapa, 1999). Segundo a classificação de Köppen, o clima é do tipo Aw, ou seja, tropical úmido com verão chuvoso e inverno seco, sendo a temperatura do mês mais frio superior a $18{ }^{\circ} \mathrm{C}$. As médias anuais de precipitação, temperatura e umidade relativa do ar são, respectivamente, $1023 \mathrm{~mm}, 24^{\circ} \mathrm{C}$ e $77 \%$.

O plantio foi realizadono dia 5 de agosto de 2005 e a colheita em 17 de agosto de 2006, utilizando-se a variedade RB5536 no espaçamento de 1,40 m entre linhas, mantendo-se 13 gemas por metro. Foi utilizada cana planta, com variedade precoce, com o objetivo de produzir canas sementes para plantio de outras áreas. 
No local, foi instalada uma Estação Micrometeorológica Automática - EMA, para medidas das diferentes variáveis: temperatura e umidade do ar, velocidade do vento, fluxo de calor no solo, saldo de radiação (Rn) e irradiância solar (incidente e refletida).

A irradiância solar incidente (Rs $\downarrow$ ) e a refletida pela superfície (Rs $\uparrow$ ) foram medidas por meio de 2 piranômetros LI-200X (Li-Cor, Lincoln, NE, USA), enquanto o saldo de radiação $(\mathrm{Rn})$ foi obtido por meio de um saldo radiômetro NR-Lite (Kipp e Zonen), instalados a $2 \mathrm{~m}$ acima do dossel vegetativo, sendo ajustado sempre que necessário em função do crescimento da cultura, até o limite de $5,75 \mathrm{~m}$, aos 276 DAP quando a cana possuía 3,75 $\mathrm{m}$ de altura.

As observações de temperatura e umidade relativa do ar foram obtidas com sondas HMP35C-L (Vaisala) e as de velocidade do vento através de dois anemômetros de conchas, modelo Met One 03002 - L R. M. Young Wind Sentry Set, instalados a 0,40 e 2,40 $\mathrm{m}$ acima do dossel vegetativo e deslocados com o crescimento da cultura, permitindo-se, desta maneira, a obtenção dos gradientes de temperatura, umidade relativa do ar e velocidade do vento. O fluxo de calor no solo $(\mathrm{G})$ foi medido por meio de três fluxímetros HFP01SC-L (Hux Flux Thermal Sensors). Junto à estação, foi instalado um pluviômetro registrador da Squitter do Brasil, com 0,25mm de sensibilidade.

A aquisição e o armazenamento dos dados foram realizados por meio de um coletor de dados (datalloger) modelo CR21X (Campbell Scientific INC.).

A precipitação pluviométrica do período do experimento está mostrada na Figura 1. Embora o total de chuva tenha sido pouco maior que $600 \mathrm{~mm}$, ocorreram períodos sem chuva, e a cultura teve que receber três irrigações de $30 \mathrm{~mm}$ cada na fase de estabelecimento, com intervalos de 40 dias entre elas. No entanto, as plantas não apresentaram deficit hídrico em nenhum período.

\subsection{Balanço de Energia}

Uma vez que as leituras foram tomadas no interior da cultura para minimizar os efeitos da advecção, e sendo o termo do armazenamento e da fotossíntese pequenos em relação aos

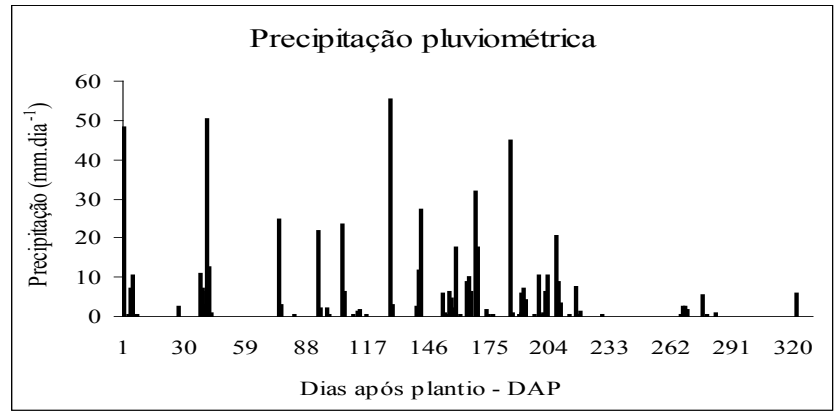

Figura 1 - Precipitação ocorrida durante o experimento. demais, a equação do balanço de energia pode ser escrita como:

$$
R_{n}-G=\lambda E+H
$$

onde $\mathrm{Rn}$ é o saldo de radiação, $\lambda \mathrm{E}$ o fluxo de calor latente (vapor d'água), $\mathrm{H}$ o fluxo de calor sensível e $\mathrm{G}$ o fluxo de calor no solo. Na resolução da Equação 1, considera-se tudo o que chega à superfície como positivo e tudo o que sai como negativo. Os fluxos por unidade de área, apresentados do lado esquerdo da Equação 1 são considerados como energia disponível e do lado direito, como energia turbulenta. Uma das maneiras de resolver a equação é por meio da utilização da razão de Bowen, que é obtida como a razão entre os fluxos turbulentos de calor sensível e latente.

Entretanto, neste trabalho o fluxo de vapor foi obtido pelo método de Penman e Monteith e o fluxo de calor sensível (H) estimado como resíduo na Equação 1.

\section{3 Método de Penman e Monteith}

A conhecida equação de Penman e Monteith (Monteith, 1981), estima o fluxo de calor latente $-\lambda \mathrm{E}\left(\mathrm{W} \mathrm{m}^{-2}\right)$, por:

$$
\lambda E=\frac{s R n+\rho c_{p} \Delta e}{s+\gamma\left(1+r_{c} / r_{a}\right)}
$$

onde Rn é o saldo de radiação ( $\left.\mathrm{W} \mathrm{m}^{-2}\right)$, $\rho$ a massa específica do $\operatorname{ar}\left(\mathrm{kg} \cdot \mathrm{m}^{-3}\right)$ e $\mathrm{c}_{\mathrm{p}}$ é o calor específico do ar à pressão constante $\left(\mathrm{J} \mathrm{kg}^{-1} \cdot{ }^{\circ} \mathrm{C}^{-1}\right), \Delta$ e é o déficit de pressão de vapor $(\mathrm{kPa}), \gamma$ é a constante psicrométrica $\left(0,062 \mathrm{kPa} \cdot{ }^{\circ} \mathrm{C}^{-1}\right), \mathrm{r}_{\mathrm{c}}$ a resistência da cobertura vegetal $\left(\mathrm{s} . \mathrm{m}^{-1}\right), \mathrm{r}_{\mathrm{a}}$ a resistência aerodinâmica da cultura ao transporte de vapor $\left(\mathrm{s} . \mathrm{m}^{-1}\right)$ e s é tangente à curva de pressão de vapor saturante $\left(\mathrm{kPa} .{ }^{\circ} \mathrm{C}^{-1}\right)$, estimada por:

$$
s=\frac{4098 e}{(237,3+T)^{2}}
$$

onde Téa temperatura do $\operatorname{ar}\left({ }^{\circ} \mathrm{C}\right)$ e $e$ é a pressão atual de vapor $(\mathrm{kPa})$. $\mathrm{O}$ calor latente de evaporação $-\lambda\left(\mathrm{MJ} \mathrm{kg}^{-1}\right)$ é estimado por:

$$
\lambda=2,501-2,361 \times 10^{-3} T
$$

Para efeito de análise são apresentados os resultados de quatro dias típicos, um no estádio de perfilamento, dois no desenvolvimento de colmos e um na maturação, com transmissividade atmosférica acima de $50 \%$ e totais diários dos diversos componentes do balanço de energia. Os valores médios dos diversos estádios fenológicos, também serão apresentados. Todos os parâmetros derivados do balanço de energia foram estimados para o período diurno, ou seja, para Rs $\downarrow>0$. 
As fases (estádios fenológicos) considerados foram: perfilhamento, do inicio até o DAP110 (DJ 329), de desenvolvimento dos colmos, entre os DAP 111 e 275 (DJ330 a DJ 128) e de maturação dos colmos do DAP 276 até 375 (DJ 129 a DJ228).

\section{RESULTADOS E DISCUSSÃO}

Os resultados obtidos para os quatro dias característicos mostraram algumas semelhanças nas variáveis atmosféricas medidas, que podem ser destacadas inicialmente.

O dia 327/2005, com transmissividade atmosférica de 0,51 , foi selecionado para caracterizar o estádio de perfilamento, tendo apresentado os seguintes valores das variáveis atmosféricas: Temperatura máxima $29,61^{\circ} \mathrm{C}$, temperatura mínima $22,46^{\circ} \mathrm{C}$, irradiância solar global 21,21 $\mathrm{MJ} \mathrm{m}^{-2}$, saldo de radiação $13,84 \mathrm{MJ} \mathrm{m}^{-2}$.

A cultura se encontrava no estádio de perfilamento (DAP=109), apresentando um índice de área foliar (IAF) entre 2,0 e 2,5, e as plantas apresentavam altura média de $1,2 \mathrm{~m}$.

Na Figura 2 é apresentada a variação diurna dos termos do balanço de energia para o estádio de perfilamento da cultura da cana-de-açúcar.

Observando a Figura 2, pode-se perceber que o fluxo de calor latente apresentou grande variação durante o dia, representando a maior parcela do saldo de radiação. O fluxo de calor para o interior do solo mostrou pequena variação durante o dia. A regressão entre $\mathrm{G}$ e Rn, com reta passando pela origem dos eixos resultou em $G=0,091 R n$ com $R^{2}=$ 0,70. A ETP para este dia foi de $4,39 \mathrm{~mm}$.

Os totais diurnos dos termos do balanço de energia e da evapotranspiração potencial para fase de perfilamento da cana de açúcar, estão mostrados na Figura 3.

A análise da Figura 3, para o estádio de perfilamento,

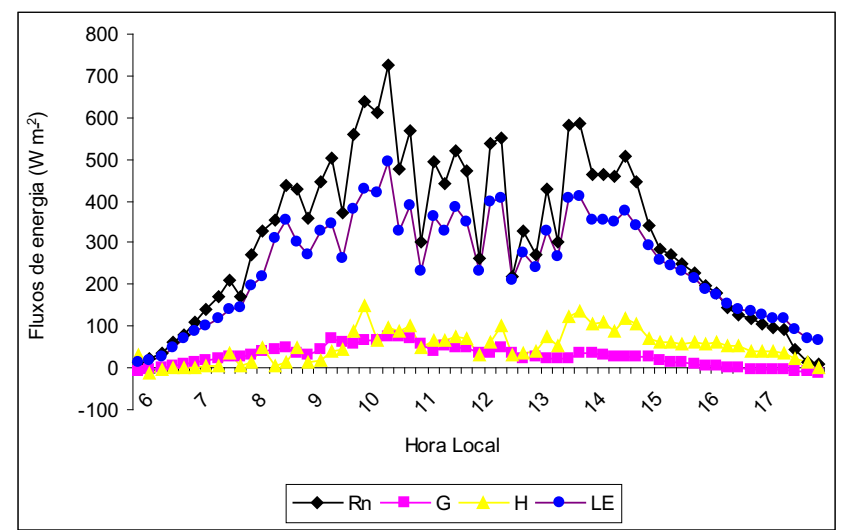

Figura 2 - Variação diurna dos componentes do balanço de energia para o estádio de perfilamento a cultura da cana-de-açúcar: Rn - saldo de radiação; $\mathrm{G}$ - densidade de fluxo de calor no solo; $\mathrm{H}$ - densidade de fluxo de calor sensível; LE - densidade de fluxo de vapor d’água. mostra que o saldo de radiação esteve em fase com o fluxo de vapor. O fluxo de calor sensível no solo apresentou valores bem pequenos. A ETo oscilou entre 3,5 e 5,5 mm neste estádio.

O dia 050/2006, com transmissividade atmosférica de 0,66 , foi um dos dias selecionados para caracterizar o estádio de desenvolvimento vegetativo (DV1), tendo apresentado os seguintes valores das variáveis atmosféricas: Temperatura máxima $34,16^{\circ} \mathrm{C}$, temperatura mínima $21,33^{\circ} \mathrm{C}$, irradiância solar global 26,14 $\mathrm{MJ} \mathrm{m}^{-2}$, saldo de radiação $17,26 \mathrm{MJ} \mathrm{m}^{-2}$.

A cultura se encontrava no estádio inicial de desenvolvimento de colmos ( $\mathrm{DAP}=197)$, apresentando um índice de área foliar (IAF) entre 6,0 e 7,0 e as plantas apresentavam altura média de $2,80 \mathrm{~m}$.

$\mathrm{Na}$ Figura 4 são apresentadas a variação diurna dos termos do balanço de energia e razão de Bowen, para fase inicial de desenvolvimento de colmos da cultura da cana-de-açúcar.

Pela Figura 4 verifica-se que o fluxo de vapor d'água mostrou uma grande variação durante o dia, representando a maior parcela do saldo de radiação. O fluxo de calor para o interior do solo mostrou pequena variação durante o dia. A regressão entre $\mathrm{G}$ e $\mathrm{Rn}$ resultou em $\mathrm{G}=0,071 \mathrm{Rn}$ com $\mathrm{R}^{2}=0,82$. A evapotranspiração potencial para este dia foi de $4,56 \mathrm{~mm}$.

O dia 113/2006, com transmissividade atmosférica de 0,69 , foi um dos dias selecionados para caracterizar o estádio de desenvolvimento vegetativo, tendo apresentado os seguintes valores das variáveis atmosféricas: temperatura máxima de $32,18^{\circ} \mathrm{C}$, temperatura mínima de $20,09^{\circ} \mathrm{C}$, irradiância solar global 18,59 $\mathrm{MJ} \mathrm{m}^{-2}$, saldo de radiação 13,56 $\mathrm{MJ} \mathrm{m}^{-2}$.

A cultura se encontrava no estádio de desenvolvimento vegetativo (DAP $=260)$, apresentando um índice de área foliar (IAF)entre 7,0e8,0,eas plantas apresentavamalturamédiade3,6m.

$\mathrm{Na}$ Figura 5 apresenta-se a variação diurna dos termos do balanço de energia para o estádio de desenvolvimento de colmos da cultura da cana-de-açúcar.

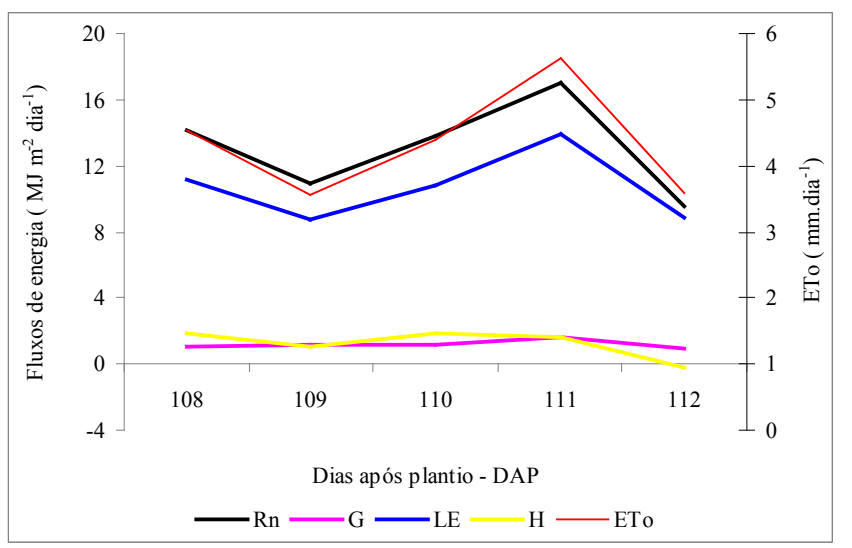

Figura 3 - Totais diurnos dos termos do balanço de energia e da evapotranspiração de referência, para fase de perfilamento da cana-deaçúcar. Rn- saldo de radiação; G- densidade de fluxo de calor no solo; LEdensidade defluxo de vapor d'água; $\mathrm{H}$-densidade de fluxo de calor sensível. 
Pela Figura 5 verifica-se que o fluxo de vapor d'água representa a maior parcela do saldo de radiação, com grande variação diurna e, o fluxo de calor sensível e o fluxo para o interior do solo possuem menor variação diária. A regressão entre $\mathrm{G}$ e $\mathrm{Rn}$ resultou em $\mathrm{G}=0,040 \mathrm{Rn}$, com $\mathrm{r}^{2}=0,77$. A ETP para este dia foi de $4,00 \mathrm{~mm}$.

Os totais diurnos dos termos do balanço de energia e da evapotranspiração potencial, para fase de desenvolvimento dos colmos, estão mostrados na Figura 6.

A análise da Figura 6, para este estádio, mostra que o saldo de radiação esteve em fase com o fluxo de vapor. $\mathrm{O}$ fluxo de calor sensível e o fluxo de calor no solo apresentaram valores bem pequenos. A evapotranspiração potencial oscilou entre 1,26 e $8,01 \mathrm{~mm} \mathrm{dia}^{-1}$.

O dia 192/2006, com transmissividade atmosférica de 0,63 , foi um dos dias selecionados para caracterizar o

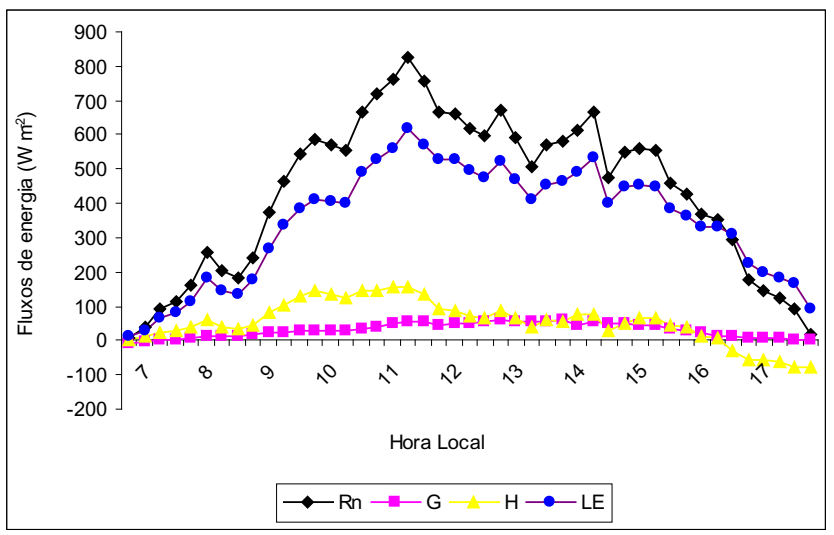

Figura 4 - Variação diurna dos componentes do balanço de energia para o estádio de desenvolvimento de colmos da cultura da cana-de-açúcar: Rn - saldo de radiação; $\mathrm{G}$-densidade de fluxo de calor no solo; $\mathrm{H}$-densidade de fluxo de calor sensível; LE - densidade de fluxo de vapor d'água.

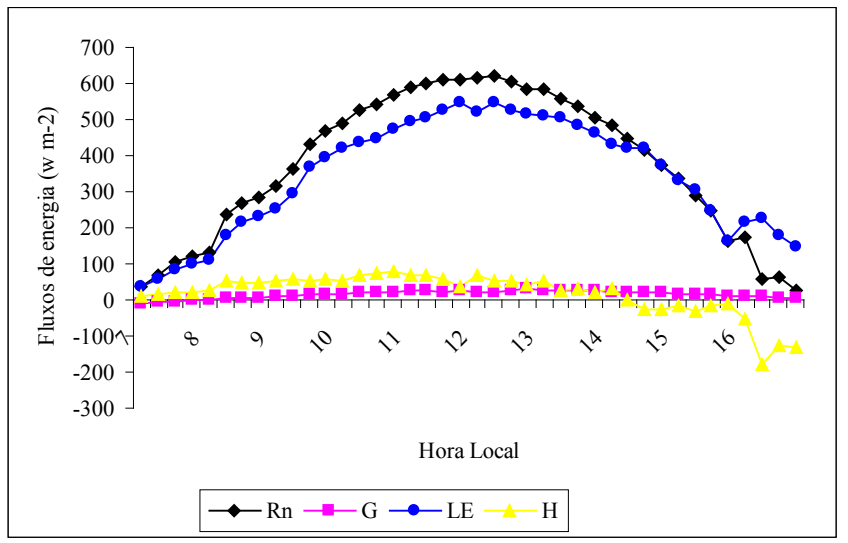

Figura 5 - Variação diurna dos componentes do balanço de energia para o estádio de desenvolvimento de colmos da cultura da cana-deaçúcar: Rn - saldo de radiação; $\mathrm{G}$ - densidade de fluxo de calor no solo; LE - densidade de fluxo de vapor d'água; $\mathrm{H}$ - densidade de fluxo de calor sensível. estádio de maturação, tendo apresentado os seguintes valores das variáveis atmosféricas: temperatura máxima $=29,1^{\circ} \mathrm{C}$, temperatura mínima $=14,47^{\circ} \mathrm{C}$, irradiância solar global 13,36 MJ m${ }^{-2}$, saldo de radiação $10,09 \mathrm{MJ} \mathrm{m}^{-2}$.

A cultura se encontrava no estádio de maturação $(\mathrm{DAP}=339)$, apresentando um índice de área foliar (IAF) entre 8,0 e 9,0, e as plantas apresentavam altura média de $3,75 \mathrm{~m}$.

Na Figura 7 é apresentada a variação diurna dos termos do balanço de energia e da evapotranspiração potencial, para fase de desenvolvimento dos colmos, da cultura da cana-de-açúcar.

Pela Figura 7 verifica-se que o fluxo de vapor d'água mostrou uma grande variação durante o dia, representando 91\% do saldo de radiação. O fluxo de calor sensível, com menor variação diurna, representou $5 \%$ do saldo de radiação. $\mathrm{O}$ fluxo de calor para o interior do solo mostrou pequena variação durante o dia representando apenas $4 \%$ do saldo de radiação.

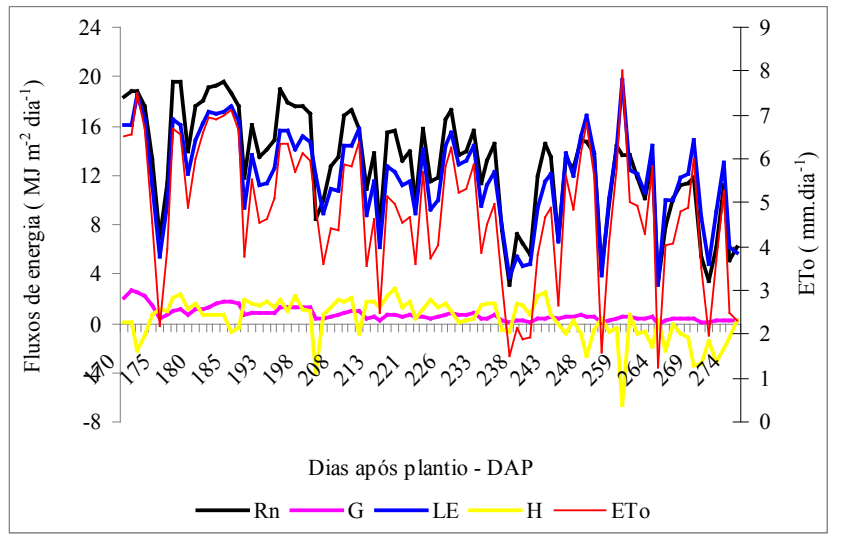

Figura 6 - Totais diurnos dos termos do balanço de energia e da evapotranspiração potencial, para fase de desenvolvimento de colmos da cana-de-açúcar. Rn- saldo de radiação; G- densidade de fluxo de calor no solo.

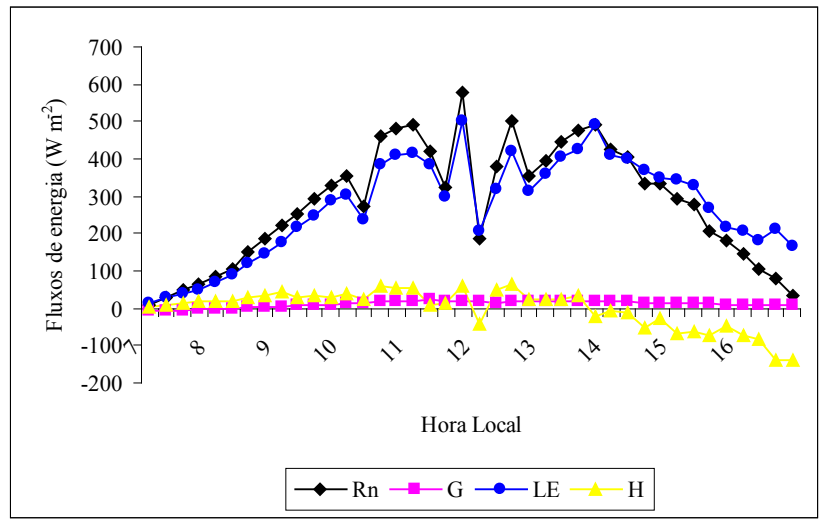

Figura 7 - Variação diurna dos componentes do balanço de energia para o estádio de maturação da cultura da cana-de-açúcar: Rn - saldo de radiação; $\mathrm{G}$ - densidade de fluxo de calor no solo; LE densidade de fluxo de vapor; $\mathrm{H}$-densidade de fluxo de calor sensível. 
A regressão entre $\mathrm{G}$ e Rn resultou em $\mathrm{G}=0,040 \mathrm{Rn}$ com $\mathrm{R}^{2}=$ 0,73 . A ETP para este dia foi de $3,27 \mathrm{~mm} \mathrm{dia}^{-1}$.

Os totais diurnos dos termos do balanço de energia, para fase de maturação, estão mostrados na Figura 8. A análise desta figura mostra que o saldo de radiação esteve em fase com o fluxo de vapor. O fluxo de calor sensível no solo apresentou valores bem pequenos. A evapotranspiração de referência oscilou entre 1,98 e $6,35 \mathrm{~mm} \mathrm{dia}^{-1}$.
Na Tabela 1 são apresentados os parâmetros derivados do balanço energia, nos estádios de perfilamento, desenvolvimento dos colmos e maturação. A partir da Tabela 1 pode-se verificar que o fluxo de vapor d'água, para os dias típicos utilizados, mostrou valores crescentes com o desenvolvimento da cultura correspondendo a 0,$78 ; 0,80 ; 0,91$ e 0,96 do saldo de radiação, e valores de 0,$79 ; 0,87 ; 0,99$ e $1,2,3$, respectivamente, para os estádios de perfilamento, desenvolvimento de

Tabela 1 - Termos do balanço de energia e da evapotranspiração potencial, para dias típicos considerados. (*) Dia escolhido para análise; DJ = Dia Juliano; $\mathrm{DAP}=$ dias após o plantio; $\mathrm{Neb}=$ nebulosidade; $\mathrm{Rn}=$ Saldo de radiação; $\mathrm{G}=$ Densidade de fluxo de calor no solo; $\mathrm{LE}=\mathrm{Densidade}$ de fluxo de calor latente; $\mathrm{H}=$ Densidade de fluxo de calor sensível; ETP = Evapotranspiração potencial; IAF = índice de área foliar; $\mathrm{h}=\mathrm{altura}$ da cultura.

\begin{tabular}{|c|c|c|c|c|c|c|c|c|c|c|c|c|c|}
\hline ANO & DJ & DAP & Neb & $\mathbf{R n}$ & G & LE & H & G/Rn & IE/Rn & Eto & IAF & h & Estádios \\
\hline & & & & $\left(\mathrm{MJ} / \mathrm{m}^{2}\right)$ & $\left(\mathrm{MJ} / \mathrm{m}^{2}\right)$ & $\left(\mathrm{MJ} / \mathrm{m}^{2}\right)$ & $\left(\mathrm{MJ} / \mathrm{m}^{2}\right)$ & & & $(\mathbf{m m})$ & & (m) & \\
\hline 2005 & 325 & 108 & 0,3 & 14,12 & 1,05 & 11,19 & 1,88 & 0,07 & 0,79 & 4,54 & & & Perfilamento \\
\hline 2005 & 326 & 109 & 0,3 & 10,98 & 1,15 & 8,77 & 1,07 & 0,10 & 0,80 & 3,55 & & & Perfilamento \\
\hline 2005 & 327 & 110 & 0,3 & 13,84 & 1,20 & 10,81 & 1,82 & 0,09 & 0,78 & 4,39 & $2,0-2,5$ & 1,20 & Perfilamento \\
\hline 2005 & 328 & 111 & 0,3 & 17,04 & 1,59 & 13,88 & 1,58 & 0,09 & 0,81 & 5,63 & & & Perfilamento \\
\hline 2005 & 331 & 114 & 0,6 & 18,05 & 0,68 & 14,06 & 3,32 & 0,04 & 0,78 & 5,70 & & & \begin{tabular}{|l|} 
Perfilamento \\
\end{tabular} \\
\hline 2005 & 334 & 117 & 0,6 & 17,52 & 1,38 & 14,49 & 1,65 & 0,08 & 0,83 & 5,88 & & & Perfilamento \\
\hline 2005 & 338 & 121 & 0,6 & 17,82 & 1,32 & 13,32 & 3,18 & 0,07 & 0,75 & 5,40 & & & Perfilamento \\
\hline 2005 & 339 & 122 & 0,6 & 19,13 & 1,32 & 14,52 & 3,31 & 0,07 & 0,76 & 5,89 & & & Perfilamento \\
\hline & & & & & & & & 0,077 & \begin{tabular}{|l|}
0,787 \\
\end{tabular} & 5,121 & & & \\
\hline 2006 & 31 & 190 & 0,6 & 19,56 & 1,08 & 16,12 & 2,36 & 0,06 & 0,82 & 6,54 & & & Des. Colmos \\
\hline 2006 & $* 35$ & 194 & 0,7 & 19,20 & 1,35 & 17,10 & 0,75 & 0,07 & 0,89 & 6,93 & & & Des. Colmos \\
\hline 2006 & 48 & 198 & 0,6 & 18,94 & 1,29 & 15,69 & 1,96 & 0,07 & 0,83 & 6,36 & & & Des. Colmos \\
\hline 2006 & 49 & 199 & 0,6 & 17,94 & 1,35 & 15,66 & 0,93 & 0,08 & 0,87 & 6,35 & & & Des. Colmos \\
\hline 2006 & 50 & 200 & 0,6 & 17,53 & 1,22 & 14,08 & 2,23 & 0,07 & 0,80 & 5,71 & $5,0-6,0$ & 2,15 & Des. Colmos \\
\hline 2006 & 76 & 226 & 0,6 & 15,82 & 0,61 & 14,04 & 1,17 & 0,04 & 0,89 & 5,69 & & & Des. Colmos \\
\hline 2006 & 79 & 229 & 0,6 & 16,60 & 0,69 & 14,35 & 1,56 & 0,04 & 0,86 & 5,82 & & & Des. Colmos \\
\hline 2006 & 80 & 230 & 0,7 & 17,27 & 0,80 & 15,41 & 1,06 & 0,05 & 0,89 & 6,25 & & & Des. Colmos \\
\hline 2006 & 83 & 233 & 0,6 & 15,57 & 0,77 & 14,45 & 0,35 & 0,05 & 0,93 & 5,86 & & & Des. Colmos \\
\hline & & & & & & & & \begin{tabular}{|l|l|}
0,057 \\
\end{tabular} & \begin{tabular}{|l|}
0,866 \\
\end{tabular} & 6,169 & & & \\
\hline 2006 & 88 & 238 & 0,6 & 14,63 & 0,69 & 12,26 & 1,67 & 0,05 & 0,84 & 4,97 & & & Des. Colmos \\
\hline 2006 & 95 & 245 & 0,6 & 14,64 & 0,52 & 13,37 & 0,75 & 0,04 & 0,91 & 5,42 & & & Des. Colmos \\
\hline 2006 & 100 & 250 & 0,6 & 14,87 & 0,61 & 15,10 & $-0,85$ & 0,04 & 1,02 & 6,12 & & & Des. Colmos \\
\hline 2006 & 101 & 251 & 0,6 & 14,73 & 0,60 & 16,83 & $-2,70$ & 0,04 & 1,14 & 6,83 & & & Des. Colmos \\
\hline 2006 & 111 & 261 & 0,6 & 14,35 & 0,38 & 14,29 & $-0,31$ & 0,03 & 1,00 & 5,79 & & & Des. Colmos \\
\hline 2006 & 113 & 263 & 0,6 & 13,57 & 0,54 & 12,37 & 0,66 & 0,04 & 0,91 & 5,01 & $7,0-8,0$ & 3,2 & Des. Colmos \\
\hline 2006 & 114 & 261 & 0,5 & 11,79 & 0,46 & 12,15 & $-0,82$ & 0,04 & 1,03 & 4,93 & & & Des. Colmos \\
\hline 2006 & 115 & 262 & 0,5 & 10,16 & 0,38 & 10,53 & $-0,76$ & 0,04 & 1,04 & 4,27 & & & Des. Colmos \\
\hline 2006 & 116 & 263 & 0,6 & 13,01 & 0,46 & 14,39 & $-1,84$ & 0,04 & 1,11 & 5,83 & & & Des. Colmos \\
\hline 2006 & 117 & 264 & 0,2 & 3,20 & $-0,10$ & 3,10 & 0,21 & $-0,03$ & 0,97 & 1,26 & & & Des. Colmos \\
\hline & & & & & & & & \begin{tabular}{|l|l|}
0,031 \\
\end{tabular} & \begin{tabular}{|l|}
0,996 \\
\end{tabular} & 5,044 & & & \\
\hline 2006 & 147 & 294 & 0,6 & 10,15 & 0,35 & 13,15 & $-3,36$ & 0,03 & 1,30 & 5,33 & & & Maturação \\
\hline 2006 & 148 & 295 & 0,6 & 10,26 & 0,48 & 12,63 & $-2,85$ & 0,05 & 1,23 & 5,12 & & & Maturação \\
\hline 2006 & 149 & 296 & 0,5 & 8,18 & 0,34 & 9,74 & $-1,91$ & 0,04 & 1,19 & 3,95 & & & Maturação \\
\hline 2006 & 150 & 297 & 0,5 & 10,10 & 0,38 & 12,42 & $-2,70$ & 0,04 & 1,23 & 5,04 & & & Maturação \\
\hline 2006 & 152 & 299 & 0,4 & 7,88 & 0,30 & 13,40 & $-5,81$ & 0,04 & 1,70 & 5,43 & & & Maturação \\
\hline 2006 & 165 & 312 & 0,5 & 9,41 & 0,31 & 10,96 & $-1,86$ & 0,03 & 1,16 & 4,44 & & & Maturação \\
\hline 2006 & 166 & 313 & 0,5 & 9,98 & 0,35 & 11,53 & $-1,90$ & 0,04 & 1,16 & 4,68 & & & Maturação \\
\hline 2006 & 184 & 331 & 0,4 & 8,33 & 0,28 & 8,70 & $-0,65$ & 0,03 & 1,04 & 3,53 & & & Maturação \\
\hline 2006 & 192 & 339 & 0,5 & 10,09 & 0,40 & 9,73 & $-0,04$ & 0,04 & 0,96 & 3,95 & $8,0-9,0$ & 3,7 & Maturação \\
\hline 2006 & 193 & 340 & 0,5 & 8,60 & 0,35 & 11,73 & $-3,48$ & 0,04 & 1,36 & 4,76 & & & Maturação \\
\hline & & & & & & & & \begin{tabular}{|l|l|}
0,038 \\
\end{tabular} & 1,234 & 4,623 & & & Maturação \\
\hline
\end{tabular}




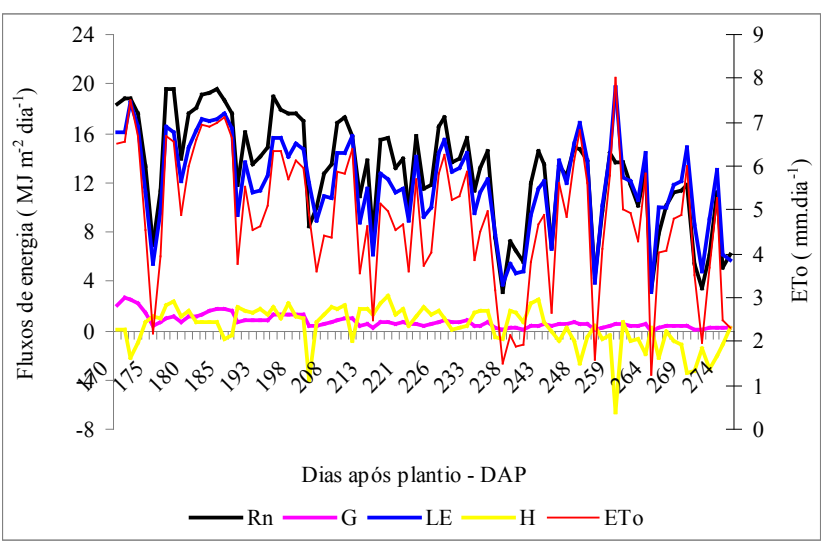

Figura 8 - Variação diurna dos termos do balanço de energia e da evapotranspiração potencial, para fase de maturação da cana-deaçúcar. Rn- saldo de radiação; G- densidade de fluxo de calor no solo; LE- densidade de fluxo de vapor d'água; H- densidade de fluxo de calor sensível.

colmos e maturação. Nota-se que a advecção de calor sensível colaborou no processo evaporativo na última fase.

\section{CONCLUSÕES}

Não houve mudanças no comportamento dos termos do balanço de energia, quando se consideraram os diferentes estádios de desenvolvimento da cultura, embora os valores absolutos dos termos tenham sido diferentes.

Para os dias típicos estudados o fluxo de vapor d'água representou 0,78 da Rn para o 109 DAP, 0,80 de Rn, para o 197 DAP, 0,91 da Rn para o 260 DAP e 0,96 da Rn, para o 339 DAP.

O fluxo de vapor d'água mostrou valores médios para os estádios de 0,$79 ; 0,87 ; 0,99$ e 1,2 do saldo de radiação, para as fases de perfilamento, desenvolvimento de colmos e maturação, respectivamente.

A evapotranspiração potencial apresentou valores médios de $5,12 \mathrm{~mm}, 6,17 \mathrm{~mm}, 5,04 \mathrm{~mm}$ e 4,62 para as fases de perfilamento, desenvolvimento de colmos e maturação, respectivamente.

\section{REFERÊNCIAS BIBLIOGRÁFICAS}

ALFONSI, R.R. et al. Balanço de energia em milho. Pesquisa Agropecuária Brasileira, Brasília, v.21, n.12, p. 1233-5, 1986.

BERGAMASCHI, H., OMETTO,J.C., VIEIRA, H.H. Deficiência hídrica em feijoeiro, II. Balanço de energia. Pesquisa Agropecuária Brasileira, Brasília, v.23, n.7, p. 745-57, 1988.

CUNHA, G. R., BERGAMACHI, H. Balanço de energia em alfafa. Revista Brasileira de Agrometeorologia.,Santa Maria, v.2, p.9-16, 1994.
CUNHA, G. R., BERGAMACHI, H., BERLATO, M.A. Balanço de energia em cultura de milho: Estudo de casos. In: CONGRESSO BRASILEIRO DE AGROMETEOROLOGIA, 6, 1989. Maceió, AL. Anais..., São José dos Campos: Sociedade Brasileira de Agrometeorologia, 1989. p.417-26.

EMBRAPA - Centro Nacional de Pesquisa de Solos. Sistema Brasileiro de Classificação de Solos - Brasília, DF. Embrapa Produção de Informação; Rio de Janeiro. 412 p, 1999.

FONTANA, D.C., BERLATO, M.A., Bergamaschi, H. Balanço de energia em soja irrigada e não irrigada. Pesq. Agropec. Brasileira, Brasília. v.26, n.3, p.403-10, 1991.

FROTA, P. C. E. Estudo do calor sensível e latente no interior de uma cultura de milho (Zea mays, L.), Dissertação ( Mestrado em Agrometeorologia), ESALQ/USP, Piracicaba-SP. 1978.

MENDONÇA J. C. Estimação da evapotranspiração regional utilizando imagens digitais orbitais da região Norte Fluminense, RJ. Tese (Doutorado em Produção Vegetal) - Universidade Estadual do Norte Fluminense "Darcy Ribeiro". 145 p., 2007.

MONTEITH, J. L. Evaporation and surface temperature. Q.J. Royal Meteorological Society, London. v.107, p. 1-27, 1981. MOURA, M. S. B. ; SOARES, J. M. ; GURGEL, M. T. ; SILVA, THIERES GEORGE FREIRE DA . Balanço de energia na cana-de-açúcar irrigada no Sub-médio São Francisco. In: CONGRESSO NACIONAL DE IRRIGAÇÃO E DRENAGEM, 17, 2007. Mossoró, RN. Anais..., XVII CONIRD - Agricultura Irrigada no Semi-Árido, 2007.

OLIVEIRA, F.A., SILVA, J.J.S. Evapotranspiração, índice de área foliar e desenvolvimento radicular do feijão irrigado, Pesquisa agropecuária brasileira, Brasília, v.25, n.3, p.31722, 1990.

PEDRO JUNIOR, M. J. Balanço de energia em soja (Glycine max L. Merril). Dissertação (Mestrado em Solos e Nutrição de Plantas). Escola Superior de Agricultura"Luiz de Queiroz", Universidade de São Paulo, Piracicaba, 82p. 1977.

SÁ, L.D. DE A.,VISWANADHAM, Y., MANZI, A.O. Energy flux partitioning over the Amazon Forest. Theoret. Applied Climatology, Wien, v.39, n.1, p.1-16, 1988.

TOLEDO FILHO, M.R. Estudo micrometeorológico de um cultivo de cana-de-açucar em Alagoas. Tese (doutorado em Fitotecnia). Universidade Federal do Rio Grande do Sul, $168 \mathrm{p} ., 2001$.

VILLA NOVA, N.A. Estudos sobre o balanço de energia em cultura de arroz. Tese (Livre-Docência). Escola Superior de Agricultura Luiz de Queiroz, Universidade de São Paulo, Piracicaba, 89 p.1973.

VERMA, S.B., ROSENBERG, N.J., BLAD, D.L. Turbulent exchance coefficients for sensible and water vapour under adevective conditions. Journal of Applied Meteorology, 
Boston, v.17, p.330-338, 1978

VISWANADHAM, Y., ANDRÉ, R.G.B. Energy balance of soybeans grown in Brazil. Arch. Meteorology Geophysic Bioklimatology, Ser B, Viena, v.33, p.141-57, 1983. 